\title{
CIRCULAÇÃO DO PODER-SABER NA CONSTITUIÇÃO DAS PRÁTICAS PROFISSIONAIS DE MÉDICOS E ENFERMEIROS
}

\author{
CIRCULATION OF POWER-KNOWLEDGE IN THE \\ CONSTITUTION OF PROFESSIONAL PRACTICES OF \\ PHYSICIANS AND NURSES
}

\section{CIRCULACIÓN DEL PODER-SABER EN LA CONSTITUCIÓN DE LAS PRÁCTICAS PROFESIONALES DE MÉDICOS Y ENFERMEROS}

\author{
Tauana Wazir Mattar e Silva ${ }^{1}$ \\ Isabela Silva Câncio Velloso ${ }^{2}$ \\ Meiriele Tavares Araújo ${ }^{2}$ \\ Carolina Sales Galdino ${ }^{3}$ \\ José Ferreira Pires Júnior ${ }^{4}$ \\ Thairine Aparecida de Oliveira Nobre
}

Como citar este artigo: Mattar e Silva TW, Velloso ISC, Araújo MT, Galdino CS, Pires Júnior JF, Nobre TAO. Circulação do poder-saber na constituição das práticas profissionais de médicos e enfermeiros. Rev baiana enferm. 2018;32:e-28234.

Objetivo: analisar a circulação do poder nas práticas profissionais de médicos e enfermeiros de um Centro de Terapia Intensiva. Método: pesquisa qualitativa, com dados coletados por meio de entrevista semiestruturada, com médicos e enfermeiros de Centro de Terapia Intensiva situado em Minas Gerais, Brasil, e submetidos à análise de discurso. Resultado: em geral, a equipe médica não se mostrou muito atenta às normas institucionais, sendo os enfermeiros mais envolvidos nos processos normalizadores e disciplinares. A visibilidade do médico está relacionada à legitimação do domínio do saber científico expresso em seu discurso, o que lhe confere posição de detenção do poder, à medida que o enfermeiro tem um discurso que mostra certa resistência em assumir visibilidade e protagonismo na equipe. Conclusão: o Centro de Terapia Intensiva é um cenário onde há interseção de diversos saberes especializados, que se expressam nos discursos de médicos e enfermeiros, favorecendo a circulação do poder nas práticas desses profissionais.

Descritores: Relações Médico-Enfermeiro. Poder (Psicologia). Prática Profissional. Conhecimentos, Atitudes e Prática em Saúde.

Objective: analyze the circulation of power in the professional practices of physicians and nurses of an Intensive Care Center. Method: This is a qualitative research that uses data collected through semi-structured interview with physicians and nurses of an Intensive Care Center located in Minas Gerais, Brazil, and submitted to discourse

\footnotetext{
Enfermeira. Mestre em Organização e Gestão de Serviços de Saúde e Enfermagem. Professora Assistente no Instituto de Ciências Biológicas e da Saúde do Centro Universitário UNA para o Curso de Enfermagem e Biomedicina. Belo Horizonte, Minas Gerais, Brasil. twmattar@gmail.com

2 Enfermeira. Doutora em Enfermagem. Professora Adjunta da Escola de Enfermagem da Universidade Federal de Minas Gerais. Belo Horizonte, Minas Gerais, Brasil.

Estudante de Graduação em Enfermagem. Universidade Federal de Minas Gerais. Belo Horizonte, Minas Gerais, Brasil.

Enfermeiro(a). Especialista em Estomaterapia. Belo Horizonte, Minas Gerais, Brasil.
} 
analysis. Result: in general, the medical team was not very attentive to institutional norms; therefore, nurses were the most involved in normalizing and disciplinary processes. The visibility of physicians is related to the legitimacy of the domain of scientific knowledge expressed in their discourse, which gives them a position of power, as the nurses have a discourse that shows some resistance in assuming visibility and protagonism in the team. Conclusion: Intensive Care Center is a scenario where there is an intersection of several specialized knowledge, expressed in the discourses of doctors and nurses, favoring the circulation of power in the practices of these professionals.

Descriptors: Physician-Nurses Relations. Power (Psychology). Professional Practice. Health Knowledge, Attitudes, Practice.

Objetivo: analizar la circulación del poder en prácticas profesionales de médicos y enfermeros de Centro de Terapia Intensiva. Método: investigación cualitativa, con datos recogidos por medio de entrevista semiestructurada, con médicos y enfermeros de Centro de Terapia Intensiva, en Minas Gerais, Brasil, y sometidos al análisis de discurso. Resultado: en general, el equipo médico no se mostró muy atenta a las normas institucionales, siendo los enfermeros más involucrados en procesos normalizadores y disciplinarios. La visibilidad del médico está relacionada a la legitimación del dominio del saber científico expresado en discurso, lo que le confiere posición de detención del poder, a medida que el enfermero tiene discurso que muestra cierta resistencia en asumir visibilidad y protagonismo en el equipo. Conclusión: el Centro de Terapia Intensiva es escenario donde hay intersección de diversos saberes especializados, que se expresan en discursos de médicos y enfermeros, favoreciendo la circulación del poder en las prácticas de esos profesionales.

Descriptores: Relaciones Médico-Enfermero. Poder (Psicología). Práctica Profesional. Conocimientos, Actitudes y Práctica en Salud.

\section{Introdução}

No cenário das práticas de atenção à saúde, o hospital pode ser compreendido como uma organização que incorpora avanço constante de conhecimentos científicos, aptidões, tecnologia médica, instalações e equipamentos ${ }^{(1)}$. Até o século XVIII, o hospital era um local destinado essencialmente à assistência aos pobres, mas, ao longo do tempo, constituiu-se em um ambiente voltado para a cura de doenças, no qual o médico passou a assumir papel central em sua organização e gestão $^{(2)}$.

Contemporaneamente, mesmo diante de um cenário com forte valorização do modelo médico-centrado, observa-se que as práticas interdisciplinares vêm se opondo ao reducionismo da medicina. Verifica-se também que os diversos componentes da equipe multiprofissional têm ampliado, cada vez mais, seu espaço de atuação nas práticas assistenciais e gerenciais dos hospitais $^{(3)}$. Essa ampliação do espaço de atuação pode gerar tensões entre profissionais da equipe, o que perpassa uma reconfiguração das relações de poder que se estabelecem entre médicos e enfermeiros $^{(4)}$.
Apesar de Foucault nunca ter se considerado um teórico, ele defendeu que o saber gera poder, constituindo-se, assim, o binômio poder-saber. Nas relações sociais e profissionais, esse poder legitima-se por meio do discurso, estabelecendo-se o sujeito que exerce o poder e o que se submete ou resiste a ele ${ }^{(5)}$. Nesse sentido, é o conhecimento que o sujeito detém em uma determinada situação e que é expresso por meio do discurso, que determina sua posição nas relações estabelecidas ${ }^{(6)}$.

Entretanto, o poder não tem um ponto fixo na estrutura, mas circula constantemente, assumindo posição privilegiada, nas relações profissionais, aquele que detiver maior conhecimento, isto é, maior poder ${ }^{(5)}$. No ambiente hospitalar, interagem diversos saberes profissionais, estando a prática médica em uma posição central, sendo historicamente reconhecida por possibilitar o processo de cura do corpo biológico doente. Todavia, nas atuais práticas de saúde, o enfermeiro também adquiriu destaque por seu trabalho intelectual na organização e implementação de processos assistenciais $^{(7)}$. 
Dessa forma, à medida que o poder circula, gera efeitos nas práticas de trabalho cotidianas de médicos e enfermeiros no contexto hospitalar e constitui o processo de subjetivação desses profissionais $^{(8)}$. Neste sentido, compreender as práticas de cuidado implica em buscar respostas para questionamentos que possam esclarecer como essas práticas são organizadas em um determinado contexto. Contudo, ao buscar estudos que associam as práticas de saúde com as relações de poder estabelecidas entre profissionais da saúde em Centros de Terapia Intensiva, percebeu-se que esse tema é pouco explorado, gerando uma lacuna no conhecimento.

Analisar o poder e sua circulação no cotidiano das práticas de médicos e enfermeiros corresponde a uma tentativa de explorar as próprias práticas de saúde como elementos socialmente constituídos, considerando que tais práticas estruturam-se apoiadas em relações e interações que se sustentam e se contradizem em estruturas variadas e complexas $^{(6)}$. Diante disso, o presente artigo tem como objetivo analisar a circulação do poder nas práticas profissionais de médicos e enfermeiros de um Centro de Terapia Intensiva (CTI).

\section{Método}

Este artigo é parte dos resultados da dissertação de mestrado intitulada "Configuração das Práticas de Saúde entre Médicos e Enfermeiros no Ambiente Hospitalar, na Perspectiva das Relações de Poder", defendida em 2018, na qual realizou-se uma pesquisa qualitativa, na perspectiva pós-estruturalista, com base no referencial filosófico do francês Michel Foucault. Utilizou-se o método de investigação científica que foca no caráter subjetivo do objeto analisado, por meio do discurso, na perspectiva foucaultiana.

A pesquisa foi desenvolvida no CTI de um hospital de grande porte, sem fins lucrativos, localizado no município de Belo Horizonte, Minas Gerais, que atende a pacientes do Sistema Único de Saúde (SUS), bem como àqueles advindos do sistema suplementar de saúde, comportando-se socialmente como instituição filantrópica. À época da coleta de dados da pesquisa (agosto a outubro de 2017), o CTI apresentava uma média de 170 admissões por mês, com 30 leitos de terapia intensiva e uma equipe assistencial composta por 17 enfermeiros, 100 técnicos de enfermagem, 31 médicos intensivistas e 5 residentes de medicina.

Participaram do estudo 8 médicos e 12 enfermeiros. Adotou-se como critério de inclusão o profissional integrar formalmente a equipe assistencial do CTI, independentemente do tipo de vínculo contratual, por um período no mínimo de 4 meses, restringindo-se, assim, a participação de profissionais em período de experiência. Para definição da amostra, utilizou-se o critério de saturação, que não é sustentado por parâmetros estritamente numéricos, pois nele não há, a priori, delimitação do número de participantes, sendo a amostra interrompida, quando a coleta de novos dados não mais desperta novos insights teóricos e não revela novas propriedades das categorias estabelecidas $^{(9)}$.

A coleta de dados foi feita por meio de entrevistas com roteiros semiestruturados, com algumas questões específicas para médicos e enfermeiros. Constavam das questões norteadoras direcionadas aos enfermeiros: Fale um pouco sobre o que é, para você, ser enfermeiro. O que você considera ser um bom médico? No roteiro dos médicos, tinha-se: Fale um pouco sobre o que é, para você, ser médico. O que você considera ser um bom enfermeiro? Foram questões comuns a ambos: Como são as relações entre médicos e enfermeiros no CTI, no dia a dia do trabalho? Você acredita que a forma como se estabelece a interação entre médicos e enfermeiros na unidade possibilita o melhor cuidado possível ao paciente? Por quê? Se você pudesse melhorar alguma coisa na relação médico-enfermeiro, o que você melhoraria?

Os dados foram coletados na própria instituição, durante o período de trabalho dos profissionais, de acordo com agendamento prévio junto às coordenações médica e de enfermagem, de forma que se resguardasse a rotina assistencial do setor. As entrevistas foram gravadas em equipamento Media Player. Posteriormente foram transcritas na íntegra, para análise e interpretação 
dos discursos constituídos com base nas falas dos participantes, de forma a garantir a totalidade e fidedignidade das informações.

Os dados foram analisados utilizando-se a análise de discurso (AD), metodologia que possibilita a compreensão do modo de funcionamento, os princípios de organização e as formas de produção social do sentido. A utilização da AD implica em abandonar a ideia de que somente a linguagem traz em si suas verdades. O foco pretendido é encontrar o sentido do dito, transcendendo o escrito e alcançando seu significado em um estudo sobre o contexto e as circunstâncias que o formularam ${ }^{(10)}$. Os participantes são identificados com a letra inicial da categoria, sendo E para enfermeiros e $\mathrm{M}$, para médicos, seguido do número de ordem da entrevista.

A pesquisa respeitou os preceitos éticos, acatando as Resoluções n. 466/2012 e n. 510/2016, do Conselho Nacional de Saúde. O projeto foi aprovado nos Comitês de Ética da Universidade Federal de Minas Gerais (COEP/UFMG), sob Parecer n. 2.277.728, e do hospital geral filantrópico de Belo Horizonte, escolhido como cenário da pesquisa, sob Parecer n. 2.379.540. Todos os participantes assinaram o Termo de
Consentimento Livre e Esclarecido em duas vias, sendo-lhes entregue uma delas.

\section{Resultados}

Em relação ao perfil dos participantes da pesquisa, a idade média dos enfermeiros foi de 33,5 anos e dos médicos 32,5 anos. Quanto ao sexo, $8,3 \%$ dos enfermeiros são do sexo masculino, o que, no grupo dos médicos, corresponde a 50\%. O tempo médio de atuação em CTI foi de aproximadamente 8,6 anos para os enfermeiros e 4 anos para os médicos (60\% com até 5 anos, 25\% de 6 a 10 anos e 15\% de 11 a 20 anos). Em relação ao tempo de atuação na instituição, 5\% estão há menos de 1 ano, 55\% entre 1 e 5 anos, 15\% entre 6 e 10 anos e 5\% há mais de 10 anos.

As relações de poder ou relações de força existem entre aquele que sabe e aquele que não sabe, entre a criança e seus pais, e assim por diante, estando a sociedade estruturada em milhares dessas relações. As relações de força ou de poder utilizam métodos e técnicas muito diferentes umas das outras, na procura da verdade ${ }^{(4)}$. Nesse sentido, a análise dos dados possibilitou identificar discursos de enfermeiros e de médicos que expressavam essas relações no dia a dia do CTI, conforme apresentado no Quadro $1^{5}$.

Quadro 1 - Expressões das relações de poder nos discursos de médicos e enfermeiros do Centro de Terapia Intensiva

(continua)

\begin{tabular}{|c|c|c|}
\hline Discurso & $\begin{array}{c}\text { Categoria } \\
\text { profissional }\end{array}$ & Expressões das relações de poder \\
\hline (A) & Enfermeiro & $\begin{array}{l}\text { Lidam com estresse! Um começa a xingar o outro, começa partes } \\
\text { irônicas, piadas, né?! Agressão verbal [...] parte também do enfermeiro, } \\
\text { porque chega uma hora que o enfermeiro... ele acaba, assim, } \\
\text { cansando, ficando nervoso, porque ele tá vendo a situação e, às vezes, } \\
\text { nessa situação, ele é desrespeitado, e aí ele perde, muitas vezes, a } \\
\text { razão dele. (E1). }\end{array}$ \\
\hline (B) & Enfermeiro & $\begin{array}{l}\text { [...] a gente tem, aqui no CTI [...] um bundle de punção de acesso } \\
\text { central. Então, é muito claro o que tem que fazer ali: não pode usar } \\
\text { adorno, tem que lavar as mãos, colocar capote, cobrir o paciente da } \\
\text { cabeça aos pés de campo. Às vezes, o enfermeiro, ele identifica que o } \\
\text { médico está fazendo errado, mas ele não tem coragem de falar. (E7). }\end{array}$ \\
\hline
\end{tabular}

No Quadro I, a coluna "Discurso" organiza as falas para localizá-las na seção Discussão dos resultados. Cada fala encontra-se devidamente identificada com as iniciais dos seus autores, na coluna "Expressões das relações de poder". 
Quadro 1 - Expressões das relações de poder nos discursos de médicos e enfermeiros do Centro de Terapia Intensiva

(continuação)

\begin{tabular}{|c|c|c|}
\hline Discurso & $\begin{array}{c}\text { Categoria } \\
\text { profissional }\end{array}$ & Expressões das relações de poder \\
\hline (C) & Enfermeiro & $\begin{array}{l}\text { [...] num outro serviço que eu trabalhava, eu corria leito todos os dias } \\
\text { com os médicos. Era menor o CTI, os pacientes eram menos graves. } \\
\text { Então, todos os dias, eu chegava de manhã e falava com o médico } \\
\text { que tava de plantão: - Vambora correr leito? [...] era tudo conversado, } \\
\text { tudo explicado [...] Além da corrida de leito, o médico e o enfermeiro } \\
\text { trabalhavam juntos. (E2). }\end{array}$ \\
\hline (D) & Médico & $\begin{array}{l}\text { É... tem períodos que são mais conturbados, que o plantão tá mais } \\
\text { estressante mesmo, com pacientes mais graves e aí, às vezes, acaba, em } \\
\text { alguns momentos, tendo atrito [...] Mas, na maioria das vezes, quando } \\
\text { é uma equipe boa, tanto médico, quando não tem preguiça, quanto o } \\
\text { enfermeiro que agiliza, que vê, que consegue ver as alteraçôes que o } \\
\text { médico não consegue acompanhar [...] geralmente é uma boa relação. } \\
\text { (M4). }\end{array}$ \\
\hline (E) & Médico & $\begin{array}{l}\text { É.. [quanto às normas] geralmente o enfermeiro se posiciona de } \\
\text { maneira melhor, né? O médico é um pouco mais rebelde. E acaba que } \\
\text { o enfermeiro, às vezes, tem que chamar a atenção da gente de alguma } \\
\text { norma que a gente não tá cumprindo assim [...] (M8). }\end{array}$ \\
\hline (F) & Médico & $\begin{array}{l}\text { O enfermeiro, ele tem que ser, acima de tudo, uma pessoa com aptidões } \\
\text { para gerenciar [...] e isso requer dar atribuiçôes, elogiar, chamar } \\
\text { atenção dos técnicos, é... puxar a orelha do médico, da fisioterapeuta. } \\
\text { E, pra isso, ele tem que ter uma boa habilidade comunicativa também, } \\
\text { né? Tem que saber como falar e o que falar. (M2). }\end{array}$ \\
\hline (G) & Enfermeiro & $\begin{array}{l}\text { [...] como o nosso fluxo de médicos nem sempre roda [...] ele acaba } \\
\text { conhecendo o seu serviço. Então, eu acho que gera uma confiança } \\
\text { no nosso serviço pra eles também [...] Então, assim, se eu ir lá, avaliar, } \\
\text { questionar uma coisa e debater, eu acho que épor isso que eles } \\
\text { aceitam. Eu num só vejo só pra mim e deixo eles resolverem. Tem o } \\
\text { meu posicionamento perante eles [...] a gente discute na maioria das } \\
\text { vezes, quando eles veem... Assim, eles aceitam nossa opinião, né? (E8). }\end{array}$ \\
\hline (H) & Enfermeiro & $\begin{array}{l}\text { [...] os dois [médicos e enfermeiros] têm que falar... a mesma lingua, } \\
\text { apesar de terem funçôes diferentes e conbecimentos cada um dentro } \\
\text { da sua área específica. Quem se beneficia é o paciente. (E1). }\end{array}$ \\
\hline (I) & Médico & $\begin{array}{l}\text { [...] um completa o serviço do outro mesmo, né? Todos têm sua } \\
\text { importância e são necessários no ambiente. Então, eu acho que a } \\
\text { gente tem que respeitar, né? Trabalhar junto mesmo. (M3). }\end{array}$ \\
\hline (J) & Enfermeiro & $\begin{array}{l}\text { Então, assim, aqui, no inicio [...] tinha corrida de leito. Eu via que eles } \\
\text { quase não olhavam pro enfermeiro. Assim, sabe, e... dai eu comecei a } \\
\text { me posicionar, levantar a mão, a falar o que eu percebia do paciente, } \\
\text { né? [...] Então, eu percebi que houve uma receptividade, depois de um } \\
\text { tempo. Não foi de cara, né? [...] Eu acho que o paciente tem muito } \\
\text { a ganhar. Então, assim, eu tenho pessoas que exigem mais de mim } \\
\text { enquanto enfermeira, né? Que eu posso dizer que aproveitam mais do } \\
\text { meu conhecimento, né? E tem médicos que não. (E5). }\end{array}$ \\
\hline (K) & Enfermeiro & $\begin{array}{l}\text { Olha, eu acho que a gente poderia melhorar a questão da } \\
\text { comunicação, né? [...], é... [o médico] chamar o enfermeiro mesmo, } \\
\text { pra ser mais ativo no dia a dia [...] (E12). }\end{array}$ \\
\hline (L) & Enfermeiro & $\begin{array}{l}\text { [...] o médico tem que ser parceiro da equipe; ele tem que chegar, ele } \\
\text { tem que mostrar primeiro o conhecimento que ele tem [...] Além de tudo, } \\
\text { é eles que tomam decisões, né? E diante das decisôes que eles tomam, a } \\
\text { gente tem que caminhar junto com eles. (E4). }\end{array}$ \\
\hline
\end{tabular}


Quadro 1 - Expressões das relações de poder nos discursos de médicos e enfermeiros do Centro de Terapia Intensiva

\begin{tabular}{|c|c|c|}
\hline Discurso & $\begin{array}{c}\text { Categoria } \\
\text { profissional }\end{array}$ & Expressões das relações de poder \\
\hline (M) & Enfermeiro & $\begin{array}{l}\text { Então, tem os protocolos, a questão de punção de acesso central } \\
\text { [...] e se o médico não fizer o procedimento corretamente, a gente } \\
\text { pode comunicar com o coordenador médico. Agora o SCIH [Serviço } \\
\text { de Controle de Infecção Hospitalar] até lançou no sistema [...] um } \\
\text { documento que a gente enfermeiro preenche pra saber se o protocolo } \\
\text { de uma punção tá sendo feito igual o protocolo orienta [...] (E8). }\end{array}$ \\
\hline$(\mathrm{N})$ & Enfermeiro & $\begin{array}{l}\text { [risos] Bom [...] eu já tive situações aonde o médico começou a colocar } \\
\text { pra mim tudo que ele já tinha pensado em termos de raciocínio, } \\
\text { porque o paciente não tava tendo uma evolução favorável, e dai ele foi } \\
\text { me perguntar: - [...] o que o você acha? Eu esqueci de alguma coisa? } \\
\text { Ou seja, ele tava me usando pra ajudar ele no raciocínio [...] (E5). }\end{array}$ \\
\hline (O) & Médico & $\begin{array}{l}\text { É de uma relação de equipe mesmo, de um ajudar o outro; de ajudar } \\
\text { tanto no diagnóstico, no procedimento, na impressão do paciente. } \\
\text { Então, eu acho que dessa forma fica um trabalho interessante. (M8). }\end{array}$ \\
\hline
\end{tabular}

Fonte: Elaboração própria.

Considerando-se que as relações de poder estão presentes em todas as relações humanas e não se restringem a relações específicas, certamente não houve intenção de esgotar a discussão sobre a configuração das práticas de saúde na perspectiva das relações de poder no CTI, mas de identificar nuances dessas relações que se apresentam de forma expressiva no delineamento da estrutura do trabalho e na configuração das relações das equipes.

\section{Discussão}

Pela lente filosófica de Foucault, as relações de poder estão intrinsecamente ligadas ao saber ou conhecimento, constituindo o binômio poder-saber ${ }^{(5)}$. O saber, ou conhecimento, é aquilo sobre o que podemos falar, com domínio e propriedade, em uma prática discursiva, e que delineia as relações de $\operatorname{poder}^{(4)}$, de forma que o saber legitimado pelo discurso de determinado indivíduo é reconhecido como verdadeiro por seus pares e confere-lhe poder nas relações estabelecidas $^{(5)}$. Entretanto, é importante considerar que o poder circula, à medida que diferentes sujeitos constituem seus discursos de verdade, legitimando diferentes conhecimentos e verdades, em diferentes momentos e situações ${ }^{(11)}$.
Nesse sentido, em diversas práticas discursivas dos profissionais que participaram desta pesquisa, percebeu-se um esforço de legitimação de seus discursos de verdade, o que, não raro, está associado a situações de conflito (Discurso A - Quadro 1). No discurso do enfermeiro, relações conflituosas entre esses profissionais e os médicos, em determinadas ocasiões, são enfrentadas com atitudes de desrespeito, ironia e agressão verbal, de forma que o enfermeiro, vencido pelo cansaço, sujeita-se a uma situação que lhe é desfavorável, sem que se aproprie de discursos que evidenciem seu conhecimento para delimitar seu espaço e reconhecimento profissional (Discurso B - Quadro 1).

O reconhecimento profissional está associado à visibilidade social alcançada, ao longo da história, pela classe médica, devido à legitimação de seu saber científico, expresso por seu domínio das doenças e seus respectivos tratamentos, bem como de técnicas que curam e salvam vidas ${ }^{(4)}$. Entretanto, Foucault considera que os acontecimentos que geram saber devem ser considerados em seu tempo, história e espaço ${ }^{(4)}$, de modo que as relações de poder também devem ser analisadas considerando-se esses elementos. Isso significa dizer que o conhecimento não é definitivo e permanente, de modo que pode sofrer 
alteração, modificando-se também as relações de poder por ele sustentadas ${ }^{(5)}$.

Nessa perspectiva, um enfermeiro participante do estudo reconheceu que as práticas vivenciadas por ele, anteriormente, em um CTI de menor porte, com menor número de pacientes internados e com quadros clínicos menos graves, possibilitavam uma atuação mais integrada da equipe, com melhor otimização do trabalho (Discurso C - Quadro 1), o que favorecia a harmonia do ambiente. Em um ambiente de trabalho em saúde harmônico, a possibilidade de que médicos e enfermeiros concentrem-se efetivamente no paciente ${ }^{(12)}$ é maximizada, com consequente redução do impacto de possíveis efeitos negativos das relações profissionais na qualidade do cuidado prestado e na segurança do paciente ${ }^{(13)}$.

Entretanto, não é possível negar que, embora o CTI seja o local ideal para o cuidado de pacientes agudos com quadros graves recuperáveis, seu ambiente é um dos mais tensos e traumatizantes do hospital, tanto para pacientes e familiares quanto para os próprios profissionais ${ }^{(14)}$. Nesse sentido, pode-se inferir que a dinâmica e a logística da terapia intensiva são mecanismos que normatizam as relações entre os profissionais que lá exercem suas atividades, estando a dinâmica cotidiana condicionada à forma de cada um reagir a esse ambiente. Nesse contexto, a "preguiça do médico" e a "habilidade do enfermeiro" para agilizar os processos aparecem no discurso médico como elementos que delineiam as relações profissionais (Discurso D - Quadro 1). Observa-se, no discurso do médico, que a fluidez da relação profissional está condicionada à sua expectativa em relação à participação do enfermeiro no cuidado prestado, o que está associado à capacidade daquele profissional para perceber alterações clínicas não percebidas pelo próprio médico.

Outra importante forma de exercício do poder é a disciplina ou poder disciplinar. A disciplina pode ser compreendida como uma técnica de poder que atravessa todas as instituições, na qual se utiliza da vigilância constante e da punição como mecanismos de adestramento dos corpos, docilizando-os e adequando-os à melhor utilização em um determinado contexto, de acordo com as normas estabelecidas ${ }^{(15)}$.

O enfermeiro é um profissional reconhecido pela equipe como mais afeito a viabilizar os processos de cuidado, tendo como base normas disciplinadoras (Discursos B e E - Quadro 1). Observa-se, nos discursos, que o enfermeiro, por meio da vigilância, tem a possibilidade de assumir um papel de autoridade diante de procedimentos médicos. Isso ocorre porque ele detém conhecimento sobre as normas estabelecidas, mesmo quando se referem a procedimentos realizados exclusivamente pelo profissional médico. Entretanto, mesmo reconhecendo-se o papel do enfermeiro como sujeito central na manutenção da ordem disciplinar do CTI, é importante ressaltar que esse conhecimento não lhe garante uma postura ativa diante da equipe, capaz de efetivamente minimizar riscos para o paciente. Isso conduz a uma reflexão acerca da importância de que se associe a esse conhecimento os próprios saberes que fundamentam determinada normatização.

A "rebeldia" dos profissionais da classe médica é naturalizada no discurso do próprio (Discurso E - Quadro 1) e utilizada como uma justificativa para sua não adesão às normas. Além disso, está subentendida a submissão do enfermeiro à norma e seu papel, também naturalizado, de zelar para que essas normas sejam cumpridas pela equipe médica. Decerto, pode não se tratar de uma reflexão consciente, mas enuncia, sutilmente, a supremacia médica.

Também há que se considerar que a habilidade para gestão é percebida como um pré-requisito para a prática profissional do enfermeiro. Entretanto, essa habilidade gestora é associada, no discurso, à capacidade de comunicação para reportar elogios e aplicar penalidades (Discurso F - Quadro 1). A aplicação de penalidades disciplinares é definida por Foucault ${ }^{(5)}$ como a sanção normalizadora, a qual busca punir os sujeitos pelos seus desvios, com o intuito também de prevenir que novas falhas ocorram, em uma mecânica de castigo representada por um processo que passa pela expiação 
e arrependimento, objetivando a não repetição da falha ou erro.

Entretanto, mesmo diante da supremacia médica, o enfermeiro reconhece ser possível assumir uma posição diferenciada nas relações de poder por meio de um discurso que evidencie seu conhecimento, o que também é favorecido por um maior período de tempo de trabalho conjunto da equipe (Discurso G - Quadro 1). Está posto que a experiência de trabalho com o médico por algum tempo suscita oportunidades de o enfermeiro evidenciar seu potencial produtivo na equipe, bem como seu nível de conhecimento. Nesse sentido, estudos apontam que, de fato, quanto maior o tempo de contato entre os profissionais, mais fortalecido se torna o grupo, o trabalho em equipe, a amizade e o companheirismo, estabelecendo-se maior confiança ${ }^{(16,17)}$.

Observa-se, tanto no discurso do médico quanto do enfermeiro, a percepção da complementaridade do trabalho das duas categorias (Discursos H e I - Quadro 1), respeitando-se as diferenças que há entre elas, o que corrobora a ideia de que é necessário que ambos os profissionais compreendam a importância do trabalho em equipe para o melhor resultado na assistência prestada ${ }^{(18)}$. Entretanto, salienta-se que o enfermeiro é pouco percebido e demandado pelo médico em algumas atividades de elevada complexidade, como é o caso da corrida de leito, situação que assume um caráter diferenciado, quando o enfermeiro apresenta um discurso que mostra seu conhecimento acerca das práticas de saúde desenvolvidas no CTI (Discurso J - Quadro 1). A busca do enfermeiro pela participação nas corridas de leito pode ser compreendida como uma tentativa de resgate de atividades que caracterizam sua atuação no processo assistencial em sua essência, uma vez que, apesar de concentrar suas atividades em ações voltadas para a gerência do cuidado de enfermagem, ele também deve atuar na execução desse cuidado.

O esforço do enfermeiro para que essa prática seja modificada justifica-se pelo fato de a corrida de leito, com atuação da equipe interdisciplinar, otimizar a qualidade do atendimento ao paciente e potencializar a comunicação médico-enfermeiro, pois informações importantes podem ser transmitidas face a face, reduzindo, por exemplo, a necessidade de chamadas telefônicas subsequentes para esclarecimento de dúvidas ${ }^{(19)}$. No que se refere à participação do enfermeiro nessa atividade, ressalta-se que pode estar associada ao aumento de sua autoconfiança na comunicação com os médicos ${ }^{(20)}$.

Entretanto, na contramão de uma atitude que favoreça a detenção do poder pelo enfermeiro, percebe-se haver situações nas quais esse profissional assume uma postura passiva, mantendo-se em uma zona de conforto, assumindo a estabilidade da supremacia médica e sentindo-se desobrigado de assumir atitudes que modifiquem essa situação. Opta por não se expor, atribuindo, ao médico, a responsabilidade de inseri-lo no processo terapêutico, isentando-se de sua possibilidade de fazer o poder circular (Discurso K Quadro 1). Nesse contexto, cabe considerar que o poder não tem um ponto fixo na estrutura, isto é, não é detido permanentemente por um único sujeito, ao contrário, ele se constitui nas relações interpessoais, nas quais um determinado agente é capaz de conduzir a ação de outro ${ }^{(21)}$. Entretanto, é importante lembrar que o exercício do poder prescinde da liberdade daquele que sofre seu exercício; caso contrário, trata-se de dominação e não de poder ${ }^{(2,5)}$.

Tradicionalmente, o médico tende a dominar o processo de tomada de decisão terapêutica porque os próprios enfermeiros the delegam esse poder, permitindo que esse profissional assuma maior autoridade na tomada de decisão clínica $^{(17)}$. Assim, surge a expectativa, no enfermeiro, de ser acionado pelo médico, transferindo-lhe a obrigação de mobilizá-lo, de ocupá-lo, de incluí-lo no processo de cuidado.

Percebe-se, também, que o enfermeiro tem um discurso que mostra certa resistência em assumir uma posição de visibilidade e protagonismo na equipe. Coloca o médico em uma posição de preditor do cuidado, ao passo que lhe cabe "caminhar junto com ele", reafirmando, mais uma vez, a supremacia médica (Discurso L - Quadro 1). O enfermeiro assume uma postura de passividade, dispondo-se apenas a executar 
o que lhe for determinando pelo médico, não assumindo, ele próprio, responsabilidade sobre as decisões tomadas, por não ter, de certa forma, contribuído com ela. Embora médicos e enfermeiros reconheçam que o trabalho em equipe efetivo é essencial para melhorar a qualidade do cuidado do paciente ${ }^{(22-23)}$, na prática profissional, o valor atribuído à colaboração entre esses profissionais ainda é mais valorizada pelo enfermeiro $^{(22)}$.

$\mathrm{Na}$ perspectiva das relações de poder, o hospital, mais especificamente o CTI, é considerado um ambiente no qual os indivíduos estão inseridos em lugares fixos, onde os menores movimentos podem ser controlados e todos os acontecimentos são registrados ininterruptamente. Nesse contexto, o enfermeiro reconhece seu papel de controle de atividades do médico, por meio de mecanismos implantados e legitimados no serviço, com o objetivo de garantir a efetividade dos processos normatizados, podendo, ao identificar falhas em determinado procedimento, reportá-la à coordenação médica (Discurso M Quadro 1). Ao enfermeiro, foi delegado o poder de vigiar, delatar e punir, o que pode ser interpretado como um posicionamento desse profissional em um patamar superior ao do médico. Assim, percebe-se que o poder circula pelo domínio da norma e pela detenção do saber normativo $^{(4)}$.

O efetivo trabalho em equipe, com tomada de decisão compartilhada, é uma alternativa para minimizar concentração e pouca circulação do poder, que implica também em concentração de responsabilidade sobre determinados membros da equipe. Deve-se considerar ainda que há evidências de que a qualidade do cuidado prestado é diretamente proporcional à qualidade da relação entre os profissionais de saúde e que a falta de cooperação e colaboração dificulta a eficiência assistencial $^{(24)}$. Assim, a corresponsabilização sobre as práticas de cuidado dá-se por meio do compartilhamento de conhecimento, pois, da mesma forma que o poder circula pelo saber, a possibilidade de difusão das responsabilidades acontece porque o conhecimento está localizado em diferentes corpos (Discurso N
- Quadro 1). O trabalho em equipe confere o devido crédito aos diferentes profissionais e indica a circularidade do poder na rede de relações que se estabelece (Discurso O - Quadro 1), colocando em questionamento a supremacia médica absoluta. As práticas de ambos os profissionais perpassam toda uma trama composta por estratégias de posicionamento profissional, na qual, em determinada situação luta-se por maior visibilidade e, em outra, ela é alcançada e tenta-se mantê-la.

\section{Conclusão}

Com este estudo, foi possível perceber que o ambiente do CTI influencia, de forma particular, as relações profissionais, pois, por se tratar de uma área de cuidado crítico, demanda atenção concentrada, habilidade técnica e relacional, conhecimento e agilidade de todos os profissionais da equipe. Por outro lado, trata-se de um cenário no qual há interseção de diversos saberes especializados, o que favorece a circulação do poder nas práticas profissionais.

Embora haja uma estrutura formal bem definida e reconhecida pelos trabalhadores da unidade, as relações assumem amplitude e complexidade que extrapolam os limites formalmente estabelecidos, evidenciando tensões que emergem nas práticas cotidianas, apoiadas nas relações que se estabelecem entre os diversos atores em cena. Nessas relações, pode-se observar que a circulação do poder se dá à medida que os saberes são expressos nos discursos dos profissionais.

Historicamente, há um investimento do médico na manutenção de sua supremacia profissional no contexto social e econômico da saúde. Assim, o fato de a equipe médica reconhecer a importância do enfermeiro no contexto das práticas de saúde, o poder pode ser concebido não apenas como a sujeição do médico à importância do trabalho em equipe, mas também como uma estratégia de resistir aos efeitos dos dispositivos disciplinares. O poder pode circular naturalmente pelo saber e intencionalmente pela necessidade de sua preservação. 


\section{Colaborações:}

1. concepção, projeto, análise e interpretação dos dados: Tauana Wazir Mattar e Silva, Isabela Silva Câncio Velloso, Carolina Sales Galdino, José Ferreira Pires Júnior e Thairine Aparecida de Oliveira Nobre;

2. redação do artigo e revisão crítica relevante do conteúdo intelectual: Tauana Wazir Mattar e Silva, Isabela Silva Câncio Velloso e Carolina Sales Galdino;

3. aprovação final da versão a ser publicada: Tauana Wazir Mattar e Silva, Isabela Silva Câncio Velloso e Meiriele Tavares Araújo.

\section{Referências}

1. Borba GS, Kliemann Neto FJ. Gestão hospitalar: identificação das práticas de aprendizagem existentes em hospitais. Saúde Soc [Internet]. 2008 Mar [cited 2016 May 18];17(1):44-60. Available from: http://www.scielo.br/scielo.php? script=sci_arttext $\&$ pid $=S 0104-1290200800$ 0100005\&lng=en. http://dx.doi.org/10.1590/S010412902008000100005

2. Foucault M. Microfísica do poder. 28a ed. Rio de Janeiro: Paz e Terra; 2014.

3. Oliveira AM, Lemes AM, Machado CR, Silva FL, Miranda FS. Relação entre enfermeiros e médicos em hospital escola: a perspectiva dos médicos. Rev Bras Saúde Matern Infant. 2010 [cited 2016 Oct 4];10(2):433-9. Available from: http://www.scielo. br/pdf/rbsmi/v10s2/23.pdf

4. Foucault M. Arqueologia do saber. São Paulo: Edições 70; 2016.

5. Foucault M. Vigiar e punir: nascimento da prisão. 42a ed. Petrópolis: Vozes; 2014.

6. Velloso ISC, Ceci C, Alves M. Reflexões sobre relações de poder na prática de enfermagem. Rev Gaúcha Enferm [Internet]. 2010 Jun [cited 2016 May 16];31(2):388-91. Available from: http://www.scielo.br/scielo.php? script=sci_arttext \& pid=S1983-1447201 0000200026\&lng=en. http://dx.doi.org/10.1590/ S1983-14472010000200026

7. Symonds-Brown HJ, Milner MF. Breaking from Tradition: Transforming Leadership Education in Nursing. J Quality Advanc Nurs Educ - Avancées en formation infirmière [Internet]. 2015 [cited 2018
Oct 26];1(3). Available from: DOI: https://doi. org/10.17483/2368-6669.1041

8. Springer RA, Clinton ME. Doing Foucault: inquiring into nursing knowledge with Foucauldian discourse analysis. Nurs Philos [Internet]. 2015 [cited 2018 Oct 26];16:87-97. Available from: DOI: 10.1111/nup.12079

9. Minayo MCS. Sampling and saturation in qualitative research: consensuses and controversies. Rev Pesq Quali. 2017 Apr;5(7):1-12.

10. Carneiro VCV. A análise do discurso como instrumento de pesquisa para os estudos em sustentabilidade [Internet]. Trabalho apresentado no III Encontro de Ensino e Pesquisa em Administração e Contabilidade. João Pessoa; 2011. p. 1-11. Anais. Rio de Janeiro: ANPAD; 2011 [cited 2018 Oct 26]. Available from: http://www.anpad. org.br/admin/pdf/EnEPQ81.pdf

11. Bordin TM. O saber e o poder: a contribuição de Michel Foucault. Saberes. 2014;1(10):225-35.

12. Kesecioglu J. Improving the patient's environment: the ideal intensive care unit. Réanimation [Internet]. 2015 Dec [cited 2017 Sep 19];24(2):341-3. Available from: DOI: 10.1007/s13546-014-1012-8

13. Rosenstein $\mathrm{AH}, \mathrm{O}$ 'Daniel M. Impact and implications of disruptive behavior in the perioperative arena. J Am Coll Surg [Internet]. 2005 Jul [cited 2016 May 15];203(1):96-105. Available from: DOI: 10.1016/j. jamcollsurg.2006.03.027

14. Chavaglia SRR, Borges CM, Amaral EMS, Iwamoto $\mathrm{HH}$, Ohl RIB. Ambiente do centro de terapia intensiva e o trabalho da equipe de enfermagem. Rev Gaúcha Enferm [Internet]. 2011 Dec [cited 2018 Jan 12];32(4):654-61. Available from: http://www.scielo.br/scielo.php?script=sci arttext\&pid=S1983-14472011000400003\&lng=en. h t t p : / d x.doi.org/10.1590/S198314472011000400003

15. Diniz FRA, Oliveira AA. Foucault: do poder disciplinar ao biopoder. Scientia. 2014;2(3):1-217.

16. Paradis E, Leslie M, Puntillo K, Gropper M, Aboumatar HJ, Kitto $S$, et al. Delivering interprofessional care in intensive care: a scoping review of ethnographic studies. Am J Crit Care [Internet]. 2014 May [cited 2016 May 15];23(3):230-8. Available from: DOI: 10.4037/ajcc2014155

17. Tang CJ, Chan SW, Zhou WT, Liaw SY. Collaboration between hospital physicians and nurses: An integrated literature review. Int Nurs Rev 
[Internet]. 2013 May [cited 2017 Sep 23];60(3):291302. Available from: DOI: 10.1111/inr.12034

18. Machado ECM. Processo de trabalho em saúde: gestão do perfil do profissional de enfermagem. Rev Saúde e Desenvol. 2015 Jan;7(4):1-17.

19. Burns K. Nurse-physician rounds: a collaborative approach to improving communication, efficiencies, and perception of care. Medsurg Nurs. 2011 Jul-Aug;20(4):194-9.

20. Schmalenberg C, Kramer M. Nurse-physician relationships in hospitals: 20,000 nurses tell their story. Crit Care Nurse. 2009 Feb;29(1):74-85.

21. Maravilhas-Lopes SP. A gestão da informação na análise de Foucault sobre as relações poder-saber. Biblios [Internet]. 2013 [cited 2018 Oct 20];51:70-7. Available from: http://biblios.pitt.edu/ DOI 10.5195/biblios.2013.103

22. Hughes B, Fitzpatrick JJ. Nurse-physician collaboration in an acute care community hospital. J Interprof Care [Internet]. 2010 Aug [cited
2016 May 15];24(6):625-32. Available from: DOI: $10.3109 / 13561820903550804$

23. Robinson FP, Gorman G, Slimmer LW, Yudkowsky R. Perceptions of effective and ineffective nurse-physician communication in hospitals. Nurs Forum [Internet]. 2010 Aug [cited 2016 May 15];45(3):206-16. Available from: DOI: 10.1111/j.1744-6198.2010.00182.x

24. Vegesna A, Coschignano C, Hegarty SE, Karagiannis T, Polenzani L, Messina E, et al. Attitudes towards physician-nurse collaboration in a primary care team-based setting: Survey-based research conducted in the chronic care units of the Tuscany region of Italy. J Interprof Care. 2016 Jan [cited 2016 Jun 10];30(1):65-70. Available from: DOI: $10.3109 / 13561820.2015 .1081878$

Recebido: 5 de setembro de 2018

Aprovado: 4 de dezembro de 2018

Publicado: 28 de dezembro de 2018

A Revista Baiana de Enfermagem utiliza a Licença Creative Commons - Atribuição-NãoComercial 4.0 Internacional. https://creativecommons.org/licenses/by-nc/4.0/ Este artigo é de acesso aberto distribuído sob os termos da Licença Creative Commons (CC BY-NC). Esta licença permite que outros remixem, adaptem e criem a partir do seu trabalho para fins não comerciais. Embora os novos trabalhos tenham de lhe atribuir o devido crédito e não possam ser usados para fins comerciais, os usuários não têm de licenciar esses trabalhos derivados sob os mesmos termos. 